\title{
Neurological and Cardiac Manifestations of Children with Dengue Presenting to a Tertiary Care Institute: An Observational Study
}

\section{Jayashree Nadkarni, Amit Agrawal and Kiran Shrivastava}

Department of Paediatrics, Gandhi Medical College and Hamidia Hospital, Bhopal, MP, India

\author{
Correspondence: \\ Amit Agrawal \\ Department of Paediatrics, \\ Gandhi Medical College, \\ Bhopal, MP, India \\ Email: agrawaldramit@yahoo.co.in
}

DOI: $10.3126 /$ jnps.v40i3.29572

Submitted on: 2020-06-22

Accepted on: 2020-10-04

Acknowledgements: None

Funding: Nil

Conflict of Interest: None declared

Permission from IRB: Yes

To cite this article: Nadkarni J, Agrawal A, Shrivastava K. Neurological and cardiac manifestations of children with dengue presenting to a tertiary care institute: an observational study. J Nepal Paediatr Soc. 2020;40(3):224-31.

\begin{abstract}
Introduction: Dengue is a common arboviral infection in tropical areas of world with increased incidence in the past few years. Spread of disease has led to increased recognition of various atypical manifestations apart from the classical features. This study was conducted to find out the neurological and cardiac manifestations of dengue in children.
\end{abstract}

Methods: This observational study was conducted in a tertiary referral centre in Central India. Cases were classified based on the WHO 2009 Dengue guidelines for the diagnosis, treatment, prevention and control. The neurological and cardiac manifestations of dengue were studied and compared with those cases without manifestations.

Results: In this study, a total of 75 dengue cases were included and out of them, five $(6.75 \%)$ cases presented with CNS abnormalities. The most common neurological manifestations were fever with seizures, altered sensorium, vomiting and headache. Hepatomegaly, hypotension, coagulopathy, and leucocytosis $\left(>11,000\right.$ cells $\left./ \mathrm{mm}^{3}\right)$ were significantly associated with neurological dysfunction $(\mathrm{p}<0.05)$. Ten children out of 75 $(13.33 \%)$ had cardiac manifestations. They included bradycardia in five cases, tachycardia and signs of CCF in three cases and shock in two cases. Echocardiographic evaluation showed mild pericardial effusion in one patient.

Conclusions: Dengue poses a huge burden to healthcare system with its various atypical manifestations. A better understanding of neurological and cardiac clinical manifestations of dengue will reduce morbidity and mortality in such cases.

Keywords: Cardiac manifestation; Dengue; Neurological manifestations; NS1 antigen / IgM antibody

This work is licensed under creative common attribution 3.0 license

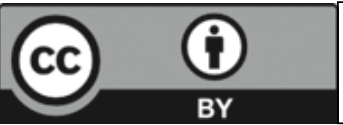

This work is licensed under creative common attribution 3.0 license 


\section{INTRODUCTION}

Dengue is a highly endemic infectious disease of tropical countries and currently contributes to a significant global burden. It is caused by any four dengue virus serotypes namely DENVs1-4, primarily transmitted to humans by the female Aedes mosquito. ${ }^{1}$ In the year 2006, WHO highlighted dengue as an emerging disease of the world. Subsequently, according to their updated report published in 2014, $40 \%$ of the world population are at risk of exposure to dengue, with $2.5 \%$ mortality amongst those needing hospitalisation. ${ }^{2}$ Globalisation, increased air travel, lack of effective mosquito control measures and unplanned urbanisation have led to an increase in its incidence with expansion of its geographic and demographic distribution. ${ }^{3}$

The clinical spectrum ranges from self-limiting influenza like illness to life threatening dengue hemorrhagic fever (DHF) and dengue shock syndrome (DSS). Though the disease can affect any age group, the severity is more in children aged below 15 years. ${ }^{4}$ DHF is currently one of the leading causes of hospitalisation and death in many tropical Asian countries. Nearly 95\% cases are among children $<15$ years; while infants comprise $5 \%$ or more of all DHF/DSS cases. ${ }^{5}$ The most severely affected population by dengue are those who live in areas with poor public health systems and are not experienced in prevention or control of the disease or its surge in intensity that often occurs seasonally. In these settings, mortality and morbidity are often higher than in regions where dengue has been endemic for decades. ${ }^{6}$

Encephalopathy and encephalitis are the most commonly reported neurological complications of dengue, with a calculated incidence varying between $0.5 \%$ and $2.6 \% .^{7}$ Cardiac involvement, although often mild, can be severe enough to result in progressive and intractable acute heart failure with global hypokinesia and acute cardiac dilatation. Lactic acidosis and calcium derangements in severe dengue can also contribute to myocardial damage. ${ }^{8,9}$ Atypical manifestations of dengue though widely reported in adults and children, are still not delineated as regards to incidence, pathogenesis, and appropriate management. Most of the studies from India are from the regions which are endemic for dengue with yearly outbreaks such as southern part of India and regions around Delhi. Madhya Pradesh is one of the populous states of the country, and although there was a dengue outbreak in October 2009 in Madhya Pradesh, there are limited studies carried out in this part of the country. ${ }^{10}$ Therefore, this observational study was planned to study the neurological and cardiac manifestations in paediatric population.

\section{METHODS}

The present study was a hospital-based observational study conducted over a period of 13 months from June 2015 to August 2016 in the Department of Paediatrics, Gandhi Medical College, Bhopal, India. It serves as a main referral centre for the district of Bhopal and its adjoining districts of Vidisha, Sehore, Ashoknagar, Sagar, Rajgarh, etc. Ethical committee clearance was obtained prior to the study from Institutional Review board (Number- 14061-63/MC/IEC/2015). A verbal and written consent was obtained from the patient's parents or guardians before recruitment into the study.

A total of 206 patients between one month and 12 years of age, admitted with clinical features of dengue-like illness were investigated for dengue infection. Dengue was suspected if the child had any of the following features: Nausea, vomiting, rashes, aches and pains, positive tourniquet test, leucopenia and any warning sign (abdominal pain or tenderness, persistent vomiting, clinical fluid accumulation, mucosal bleed, lethargy, restlessness, liver enlargement $>2 \mathrm{~cm}$, laboratory investigations: increase in haematocrit concurrent with rapid decrease in platelet count). Patients were diagnosed and classified using WHO 2009 Dengue guidelines for diagnosis, treatment, prevention and control. ${ }^{11}$ Patients with any co-existing infection along with dengue, patients with pre-existing heart disease and / or pre-existing neurological disorder were excluded from the study.

Seventy five patients, positive for dengue NS1 antigen or IgM ELISA, were included in the study and closely monitored throughout the study period. 
Detailed examination was performed in all patients to identify the multi-system involvement of the disease. Baseline laboratory investigations were obtained including complete hemogram, PCV, liver and renal function tests, serum electrolytes, random blood sugar, malarial antigen, etc. Patients that developed cardiovascular system involvement as determined by signs like arrythmias, congestive cardiac failure, cardiogenic shock, or elevated serum CK-MB were evaluated further by an electrocardiogram (ECG) and 2 D echocardiography. Patients that presented with signs of encephalopathy (altered sensorium, seizures) underwent a lumbar puncture for cerebrospinal fluid (CSF) analysis. CSF culture was carried out to rule out bacterial and fungal meningitis. Neuroimaging studies were done when feasible. Trans-fontanelle ultrasonography was performed in patients with an adequately open anterior fontanelle window. Computerised tomography (CT) and magnetic resonance imaging (MRI) of the brain was done where feasible to assess the extent of CNS involvement.

The obtained data was tabulated; data analysis was done at the end of data collection using Minitab Version 17. Patients were analysed on the basis of demographic factors like age, sex, and area of residence. Patients that presented with CVS and CNS involvement were compared with those without involvement and significant associations were sought.

\section{RESULTS}

In our study, cases that presented with fever of more than five days duration were tested for dengue and out of 206 patients, 78 cases were confirmed to have dengue infection. However, three cases were excluded from the study as one had co-existing tubercular infection and two had previously diagnosed neurological disorder. Therefore, 75 children diagnosed as dengue were included in the study, with a male to female ratio of 1.8:1. Out of them, $51(68 \%)$ cases were positive for IgM, $47(61.6 \%)$ were positive for NS1 antigen and $23(30.6 \%)$ were positive for both. The youngest patient was three months old. Table 1 depicts the age wise distribution of children based on the severity of infection. Overall mortality of $1.3 \%$ ( 1 in 75$)$ was noted in the study population.

Out of 75 cases, five $(6.75 \%)$ cases, including two females and three males, manifested with CNS abnormalities. The age range was six months to 12 years; two $(40 \%)$ patients were below one year of age. The most common manifestation was fever with seizures seen in all five patients. Hepatomegaly, hypotension, coagulopathy, and leucocytosis ( $>11,000$ cells $\left./ \mathrm{mm}^{3}\right)$ were significantly associated with the neurological dysfunction $(p<0.05)$ as shown in table 2 . Neurological features, CSF analysis, neuroimaging findings and outcome have been presented in table 3.

Cardiac manifestations were seen in $10(13.33 \%)$ out of 75 children, which included seven males and three females and a mean age of 7.6 years (range: 4 - 10 years). All the 10 cases (100\%) presented with fever followed by abdominal pain, vomiting, and diarrhoea as shown in table 4. Cough was present in one case and signs of congestive cardiac failure (CCF) were present in three patients. All three patients improved with decongestive therapy within three days. Hypotension and shock were present in two $(20 \%)$ patients along with plasma leakage features and these were treated with dopamine and milirinone infusion for two days.

All of $10(100 \%)$ patients presented with thrombocytopenia (platelets $<100,000 / \mathrm{mm}^{3}$ ) with $\mathrm{p}$ value of $<0.05$. All 10 patients had significantly

Table 1. Age wise distribution of severity

\begin{tabular}{|lrcrr|}
\hline $\begin{array}{c}\text { Age } \\
\text { group }\end{array}$ & $\begin{array}{c}\text { Dengue } \\
\text { fever }\end{array}$ & $\begin{array}{c}\text { Dengue } \\
\text { with } \\
\text { warning } \\
\text { signs }\end{array}$ & $\begin{array}{c}\text { Severe } \\
\text { dengue }\end{array}$ & $\begin{array}{l}\text { Total } \\
(\%)\end{array}$ \\
\hline$<1$ year & 6 & 2 & 6 & 14 \\
& $(8 \%)$ & $(2.7 \%)$ & $(8 \%)$ & $(18.7 \%)$ \\
$1-5$ & 5 & 7 & 3 & 15 \\
years & $(6.6 \%)$ & $(9.4 \%)$ & $(4 \%)$ & $(20 \%)$ \\
$6-10$ & 10 & 9 & 10 & 29 \\
years & $(13.3 \%)$ & $(12 \%)$ & $(13.3 \%)$ & $(38.6 \%)$ \\
$>10$ & 2 & $6(8 \%)$ & 9 & 17 \\
years & $(2.7 \%)$ & & $(12 \%)$ & $(22.7 \%)$ \\
\hline
\end{tabular}


elevated CK-MB (mean 306.9 $\pm 246.95, \mathrm{p}=0.00$ ).

ECG was performed in all 10 patients and five $(50 \%)$ were found to have sinus bradycardia and three patients with CCF had tachycardia on ECG. Bedside echocardiography facility was not available in our institution which was done after stabilisation of the patients and all except one patient had normal echocardiography findings. One patient had mild pericardial effusion without any other abnormality. None of the patient had LV dysfunction or global hypokinesia. Bradycardia resolved on recovery and no death was noted in this group.

\section{DISCUSSION}

In the past two decades, India has become endemic for dengue and many authors have reported periodic epidemic breakouts across the country. In peak seasons, any child presenting with fever can be considered to be positive for dengue. In our study, $38.6 \%$ children belonged to the age group of six to 10 years, followed by those $>10$ years $(22.6$ $\%)$. This correlates with WHO data that reports the modal age of six to eight years for low-endemic areas. ${ }^{11}$ There was a male preponderance (M:F ratio - 1.8:1) which corresponds to the results of previous studies. ${ }^{12,13}$ However, Anders KL et al. ${ }^{14}$ have reported a female predominance while Capeding M. et a ${ }^{15}$ reported no gender difference. We feel that male children engage in outdoor activities compared to females; hence, are more prone to exophilic mosquito bites. Industrialisation, increased movement of people from rural to urban areas, and environmental changes have all favoured the spread of dengue in rural as well as urban areas. ${ }^{16,17} \mathrm{We}$ found clustering of cases in the monsoon months of July to October, similar to the
Table 2. Comparison between cases without (group A) and with neurological complications (group B)

\begin{tabular}{|c|c|c|c|}
\hline Variable & $\begin{array}{c}\text { Group A } \\
(n=70) \\
(\% \text { or mean } \\
\pm \text { SD) }\end{array}$ & $\begin{array}{c}\text { Group B } \\
(n=5) \\
(\% \text { or mean } \\
\pm \text { SD) }\end{array}$ & p Value \\
\hline Rash & $33(47.14 \%)$ & $3(60 \%)$ & 0.578 \\
\hline Bleeding & $32(45.7 \%)$ & $4(80 \%)$ & 0.138 \\
\hline Vomiting & $28(40 \%)$ & $4(80 \%)$ & 0.080 \\
\hline Diarrhoea & $17(24.29 \%)$ & $2(40 \%)$ & 0.435 \\
\hline Abdominal pain & $26(37.14 \%)$ & $1(20 \%)$ & 0.440 \\
\hline Headache & $20(28.57 \%)$ & $1(20 \%)$ & 0.680 \\
\hline Third space loss & $50(71.4 \%)$ & $2(40 \%)$ & 0.141 \\
\hline Hepatomegaly & $17(24.29 \%)$ & $4(80 \%)$ & 0.007 \\
\hline Splenomegaly & $15(21.43 \%)$ & $1(20 \%)$ & 0.940 \\
\hline Hypotension & $20(26 \%)$ & $4(80 \%)$ & 0.048 \\
\hline $\begin{array}{l}\text { TLC } \\
\left(<5000 / \mathrm{mm}^{3}\right)\end{array}$ & $33(44 \%)$ & $2(40 \%)$ & 0.138 \\
\hline $\begin{array}{l}\text { TLC } \\
\left(>11,000 / \mathrm{mm}^{3}\right)\end{array}$ & $8(10.6 \%)$ & $3(60 \%)$ & 0.003 \\
\hline $\begin{array}{l}\text { Mean } \\
\text { haemoglobin } \\
(\mathrm{gm} / \mathrm{dL})\end{array}$ & $10.8 \pm 0.57$ & $12.8 \pm 0.57$ & 0.194 \\
\hline $\begin{array}{l}\text { Mean Hematocrit } \\
\text { levels }(\%)\end{array}$ & $36.59 \pm 2.83$ & $42.5 \pm 2.83$ & 0.994 \\
\hline $\begin{array}{l}\text { Thrombocyto- } \\
\text { penia } \\
(<100,000 / \mathrm{mm} 3)\end{array}$ & $32(45.71 \%)$ & $1(20 \%)$ & 0.263 \\
\hline $\begin{array}{l}\text { Serum creatinine } \\
(>1 \mathrm{mg} / \mathrm{dL})\end{array}$ & $4(5.7 \%)$ & $1(20 \%)$ & 0.216 \\
\hline $\mathrm{SGOT}>200 \mathrm{U} / \mathrm{L}$ & $20(28.5 \%)$ & $1(20 \%)$ & 0.680 \\
\hline $\mathrm{SGPT}>200 \mathrm{U} / \mathrm{L}$ & $11(15.7)$ & $1(20 \%)$ & 0.801 \\
\hline $\begin{array}{l}\text { Cougulopathy } \\
\text { (Abnormal PT/ } \\
\text { aPTT) }\end{array}$ & $14(20 \%)$ & $5(100 \%)$ & 0.001 \\
\hline $\begin{array}{l}\text { Mean serum } \\
\text { Sodium } \\
(\mathrm{mEq} / \mathrm{L})\end{array}$ & $139.73 \pm 7.07$ & $132 \pm 7.07$ & 0.537 \\
\hline $\begin{array}{l}\text { Mean serum } \\
\text { Potassium } \\
(\mathrm{mEq} / \mathrm{L})\end{array}$ & $4.25 \pm 0.99$ & $4.2 \pm 0.99$ & 0.694 \\
\hline
\end{tabular}

Table 3. Clinical profile of patients with neurological manifestations

\begin{tabular}{|lllll}
\hline Age/ Sex & Neurologial features & CSF & Neuroimaging & Outcome/ follow-up \\
\hline $20 \mathrm{mo} / \mathrm{F}$ & Seizures, altered sensorium & Aseptic meningitis & CT head - cerebral edema & Complete recovery \\
$9 \mathrm{mo} / \mathrm{M}$ & Seizures, hemiparesis & Normal & USG cranium - IVH & $\begin{array}{l}\text { Residual hemiparesis, } \\
\text { lost to follow-up }\end{array}$ \\
$11 \mathrm{y} / \mathrm{M}$ & Seizures, headache & Normal & MRI brain - normal & Complete recovery \\
$6 \mathrm{mo} / \mathrm{M}$ & Seizures, altered sensorium & Aseptic meningitis & Not done & LAMA \\
$12 \mathrm{y} / \mathrm{F}$ & $\begin{array}{l}\text { Seizures, headache, altered } \\
\text { sensorium, hemiparesis }\end{array}$ & Normal & Could not be done & Expiry due to MODS
\end{tabular}


Table 4.Comparison between cases without (group A) and with cardiac complications (group B)

\begin{tabular}{|c|c|c|c|c|}
\hline Variable & $\begin{array}{l}\text { Group } A(n=65) \\
(\% \text { or mean } \pm \text { SD) }\end{array}$ & $\begin{array}{l}\text { Group B }(n=10) \\
(\% \text { or mean } \pm \text { SD) }\end{array}$ & Odds Ratio* & P Value \\
\hline Rash & $31(47.69 \%)$ & $5(50 \%)$ & 1.10 & 0.892 \\
\hline Bleeding & $32(49.23 \%)$ & $6(60 \%)$ & 0.26 & 0.84 \\
\hline Vomiting & $28(43.08 \%)$ & $4(40 \%)$ & 0.88 & 0.855 \\
\hline Diarrhoea & $17(26.15 \%)$ & $2(20 \%)$ & 0.71 & 0.677 \\
\hline Abdominal Pain & $23(35.38 \%)$ & $5(50 \%)$ & 1.83 & 0.374 \\
\hline Cough & $8(12.31 \%)$ & $1(10 \%)$ & 0.79 & 0.834 \\
\hline Third space loss & $25(38.46 \%)$ & $2(20 \%)$ & 0.40 & 0.258 \\
\hline Hepatomegaly & $18(27.69 \%)$ & $2(20 \%)$ & 0.65 & 0.69 \\
\hline Splenomegaly & $14(21.54 \%)$ & $2(20 \%)$ & 0.91 & 0.912 \\
\hline Shock & $11(16.92 \%)$ & $2(20 \%)$ & 1.23 & 0.811 \\
\hline Edema & $46(70.76 \%)$ & $5(50 \%)$ & 0.413 & 0.190 \\
\hline Leucocytosis $\left(>11,000 / \mathrm{mm}^{3}\right)$ & $10(15.38 \%)$ & $0(0 \%)$ & 0.25 & 0.506 \\
\hline Leucopenia $\left(<5000 / \mathrm{mm}^{3}\right)$ & $11(16.92 \%)$ & $4(40 \%)$ & 3.27 & 0.089 \\
\hline Mean hemoglobin $(\mathrm{gm} / \mathrm{dL})$ & $10.82 \pm 5.47$ & $11.35 \pm 1.28$ & & 0.37 \\
\hline Mean hematocrit (\%) & $36.48 \pm 24.94$ & $37.5 \pm 3.63$ & & 0.54 \\
\hline Thrombocytopenia $\left(<100,000 / \mathrm{mm}^{3}\right)$ & $29(44.62 \%)$ & $10(100 \%)$ & 25.98 & 0.016 \\
\hline aPTT & $11(16.92 \%)$ & $1(10 \%)$ & 0.55 & 0.578 \\
\hline INR & $14(21.54 \%)$ & $1(10 \%)$ & 0.40 & 0.396 \\
\hline Mean serum Potassium $(\mathrm{mEq} / \mathrm{L})$ & $4.24 \pm 1.54$ & $4.13 \pm 0.69$ & & 0.66 \\
\hline Mean serum Sodium $(\mathrm{mEq} / \mathrm{L})$ & $139.46 \pm 78.47$ & $140.9 \pm 6.87$ & & 0.58 \\
\hline
\end{tabular}

epidemiology noted in this part of Asia. ${ }^{18}$

In this study, five cases presented with CNS manifestations which is higher than that reported by Solomon et al $(1 \%)^{19}$ and Soares et al. $(1.3 \%){ }^{20}$ The most common manifestation was fever with seizures $(100 \%)$ followed by altered sensorium $(60 \%)$, vomiting $(60 \%)$ and headache $(40 \%)$. These findings were in accordance with the observations made by Kakoti $\mathrm{G}$ et al. ${ }^{17}$ Sahu R et al. ${ }^{21}$, and Cam et al. $^{22}$, who have reported thrombocytopenia, and raised haematocrit to be significantly related to neurological manifestations in dengue. Similarly in our study, hepatomegaly, hypotension, coagulopathy, and leucocytosis $\left(>11,000 / \mathrm{mm}^{3}\right)$ were found to be significantly associated with neurological dysfunction in dengue patients $(p<$ 0.05). CSF analysis performed in cases with CNS involvement was suggestive of aseptic meningitis in two patients; dengue encephalitis to be specific; however, treatment plan remained same for all patients with encephalopathy. This may have been an underestimation as CSF analysis was delayed in two patients due to coagulopathy. Also, we could not test for dengue IgM antibody in CSF due to non-availability of the investigation in our set-up.

Soares C et al. ${ }^{20}$ reported cranial CT to be normal in all patients, except for one, that revealed cerebral edema. Kumar $\mathrm{R}$ et al. ${ }^{23}$ reported five cases with intracranial haemorrhage. In our study, neuroimaging was performed in three patients; out of them one had a normal MRI brain, one patient had features of cerebral edema on CT scan and one infant had IVH. Unfortunately we could not perform neuroimaging in two patients. Mortality 
among children with viral encephalitis is extraordinarily high in South-east Asia ranging from 17 to $50 \%{ }^{17}$

Our study reported mortality rate of $20 \%$ in patients presenting with neurological features where an infant who presented with a 10 day history of fever and altered sensorium, rapidly developed multiorgan dysfunction and succumbed to death. It is noteworthy to mention that a child with prolonged fever with worsening clinical picture could be due to hemophagocytic lymphohistiocytosis (HLH) - a complication of dengue. ${ }^{24}$ Kakoti $\mathrm{G}$ et al. ${ }^{17}$ reported $27 \%$ death due to dengue encephalitis. The high mortality in this setting may be due to late reporting of cases or due to unavailability of standard neurointensive care facilities.

Literature suggests cardiac involvement in $15-52 \%$ of dengue patients. ${ }^{25-28}$ In the present study, 10 out of $75(13.33 \%)$ children had cardiac manifestations of whom seven $(70 \%)$ were males and three $(30 \%)$ were females. As per previous studies, fever, rashes, positive tourniquet test, pleural effusion, ascites, chest pain, skin flush are associated manifestations in patients with cardiac problems. ${ }^{26,28}$ With increasing severity of the disease, acute heart failure, chest pain, hypotension and shock become evident. ${ }^{26}$ The most common presentation in these patients was fever $(100 \%)$ followed by rashes $(50 \%)$. In $70 \%$ of patients tourniquet test was positive while $60 \%$ patients had bleeding episodes; however, there was no difference in the clinical features between cardiac and non-cardiac groups. However, Kulratne $\mathrm{S}$ et al. ${ }^{28}$ reported significant chest pain and skin flush in their cardiac group. Miranda $\mathrm{CH}$ et al. ${ }^{26}$ reported cardiac manifestations in $10 \%$ patients such as acute heart failure, chest pain, hypotension and shock. We believe that the cases admitted in our study were with mild cardiac manifestations and hence, they recovered and no mortality was noticed in this group.

In our study, CK-MB was evaluated only in patients with cardiac manifestations, we found thrombocytopenia and elevated CK-MB in all 10 $(100 \%)$ patients, leukopenia in four $(40 \%)$, and deranged LFT in one $(10 \%)$ patient with no derangement in RFTs or serum electrolytes.
Kulratne $\mathrm{S}$ et al. ${ }^{28}$ found no difference in parameters such as TLC, platelet counts, PCV, AST and ALT between cardiac and non-cardiac groups. Miranda $\mathrm{C}$ et $\mathrm{a}^{26}$ in their study found that patients with biomarker elevation had higher leukocyte and platelet counts along with creatinine. Wichmann D et $\mathrm{al}^{27}$ found CK-MB elevation in $14.9 \%$ cases while Gupta V et al. ${ }^{24}$ reported that $78.55 \%$ of dengue patients had elevated CK-MB levels.

Out of 10 patients, five $(50 \%)$ cases had sinus bradycardia and three patients had tachycardia which resolved on recovery. On echo, one patient had mild pericardial effusion with no LVEF dysfunction or global hypokinesia. A study by Gupta V et al. ${ }^{25}$ detected sinus bradycardia on ECG in $14.28 \%$, and sinus tachycardia in $21.4 \%$ patients with no QRS and ST changes in any patient. 2DEcho showed no reduction in LVEF; and only mild diastolic dysfunction in $14.28 \%$ patients with no systolic dysfunction or global hypokinesia. Wali et al. ${ }^{29}$ reported that $70 \%$ patients with DHF/DSS suffered diffuse left ventricular hypokinesis with a mean EF of $40 \%$. Kabra et al. ${ }^{30}$ reported that $16.7 \%$ patients with dengue illness had a decreased LVEF of $<50 \%$.

There are certain limitations in this study such as small sample size, and failure to assess dengue cases for primary and secondary infections or for infecting serotypes. Also, due to limited availability of investigations in our institution, we could not perform all the necessary investigations including torponin- $T$, viral cultures, as well as neuroimaging and bedside echocardiography on time or invasive monitoring, in all the patients. These factors limit the generalisation of the study results and therefore, we recommend further such studies in a larger sample size for a longer duration in a multi-centric setup with available advanced technologies.

\section{CONCLUSIONS}

Dengue has a self-limiting course in the majority of cases, but in the acute phase, it can present with multi-organ involvement. Patients with encephalitis like presentation should be tested for dengue whether other classical features of infection are present or not. Cases with severe dengue must be screened for cardiac involvement to anticipate and 
effectively manage myocarditis. It becomes essential on the part of treating paediatrician to suspect and have knowledge of the atypical manifestations of dengue for the early diagnosis and proper management of these patients.

\section{REFERENCES}

1. Chen R, Vasilakis N. Dengue--quo tu et quo vadis? Viruses. 2011;3(9):1562-1608. DOI:10.3390/v3091562. PMID: 21994796.

2. WHO Updates Media Centre Publications Fact Sheets No. 117. Geneva: World Health Organization; March, 2014. Available at: https://guides.library.uwa.edu.au/c.php?g=324981\&p=2178463. [last accessed on 07 Jul 2020].

3. Khetarpal N, Khanna I. Dengue Fever: Causes, Complications, and Vaccine Strategies. J Immunol Res. 2016;2016:6803098. DOI:10.1155/2016/6803098. PMID: 27525287.

4. Vazhayil PP, Stephen S, Kumar V. A retrospective Observational Study of Dengue Fever in a tertiary care centre in Kerala. Int J Sci stud. 2017;5(1):30-34. DOI: 10.17354/ijss/2017/150.

5. Halstead SB, Lan NT, Myint TT, Shwe TN, Nisalak A, Kalyanarooj S, et al. Dengue hemorrhagic fever in infants: research opportunities ignored. Emerg Infect Dis. 2002;8(12):1474-9. DOI: 10.3201/eid0812.020170. PMID: 12498666.

6. Yakoub S, Farrar J. Dengue. In: Farrar J, Hotez P, Junghanss T, Kang G, Lalloo D, White NJ, editors. Manson's Tropical Diseases. 23 ${ }^{\text {rd }}$ ed. Edinburgh: Saunders; 2014. p162-70.

7. Koshy JM, Joseph DM, John M, Mani A, Malhotra N, Abraham GM, et al. Spectrum of neurological manifestations in dengue virus infection in Northwest India. Trop Doct. 2012;42(4):191-4. doi: 10.1258/td.2012.120286. PMID: 23405004.

8. Khongphatthanayothin A, Lertsapcharoen P, Supachokchaiwattana P, La-Orkhun V, Khumtonvong A, Boonlarptaveechoke C, et al. Myocardial depression in dengue hemorrhagic fever: prevalence and clinical description. Ped Crit Care Med. 2007;8:524-9. DOI: 10.1097/01.PCC.0000288672.77782.D4. PMID: 17906598

9. Sangle SA, Dasgupta A, Ratnalikar SD, Kulkarni RV. Dengue myositis and myocarditis. Neurol India. 2010;58:598-9. DOI:10.4103/0028-3886.68664. PMID: 20739801.

10. Baruah K, Singh PK, Mohalia MM, Dhariwal AC. A study on dengue outbreak during 2009 in Bhopal and Indore districts of Madhya Pradesh, India. J Commun Dis. 2010;42(4):273-9. PMID: 22471197.

11. World Health Organisation, Special Programme for Research, Training in Tropical Diseases, World Health Organisation. Department of Control of Neglected Tropical Diseases, World Health Organisation. Epidemic, Pandemic Alert. Dengue: guidelines for diagnosis, treatment, prevention and control. World Health Organisation; 2009.

12. Pothapregada S, Kamalakannan B, Thulasingam M. Clinical Profile of Atypical Manifestations of Dengue Fever. Indian J Pediatr. 2016;83(6):493-9. DOI: 10.1007/s12098-015-1942-9. PMID: 26725457.

13. Sahana K, Sujatha R. Clinical profile of Dengue among children according to revised WHO classification: analysis of a 2012 outbreak from Southern India. Indian J Pediatr. 2014;82(2):109-13. DOI: 10.1007/s12098-014-1523-3. PMID: 24986196.

14. Anders KL, Nguyet NM, Chau NV, Hung NT, Thuy TT, Lien le B, et al. Epidemiological factors associated with dengue shock syndrome and mortality in hospitalised dengue patients in Ho Chi Minh City, Vietnam. Am J Trop Med Hyg. 2011;84(1):127-34. DOI:10.4269/ajtmh.2011.10-0476. PMID: 21212214.

15. Capeding MRZ, L'Azou M, Manalaysay M, Vince-Woo CR, Rivera RG, Sy AK, et al. Laboratory-confirmed dengue in children in three regional hospitals in the Philippines in 2009-2010. Pediatr Infect Dis J. 2015;34:114551. DOI: 10.1097/INF.0000000000000810. PMID: 26181893.

16. Katyal R, Kaushal K, Gill KS. Breeding of Aedes aegypti and its impact on Dengue/DHF in Rural Areas. WHO Regional Office for South-East Asia: National Institute of Communicable Diseases, 22 Sham Nath Marg, Delhi: Dengue Bulletin. 1997 Dec;21:93-95. 
17. Kakoti G, Dutta P, Das BR. Dengue encephalitis: an atypical manifestation of dengue fever in children. Int J Health Sci Res. 2016; 6(4):1-7.

18. Tripathi P, Kumar R, Tripathi S, Tambe JJ, Venkatesh V. Descriptive epidemiology of dengue transmission in Uttar Pradesh. Indian Pediatr. 2008;45(4):315-8. PMID: 18451453.

19. Solomon T, Dung NM, Vaughn DW, Kneen R, Thao LT, Raengsakulrach B, et al. Neurological manifestations of dengue infection. Lancet. 2000;355:1053-9. DOI: 10.1016/S0140-6736(00)02036-5. PMID: 10744091.

20. Soares CN, Faria LC, Peralta JM, de Freitas MRG, Puccioni-Sohler M. Dengue infection: neurological manifestations and cerebrospinal fluid (CSF) analysis. J Neurol Sci. 2006;249.19-24. DOI: 10.1016/j.jns. 2006.05.068. PMID: 16870213.

21. Sahu R, Verma R, Jain A, Garg RK, Singh MK, Malhotra HS, et al. Neurologic complications in dengue virus infection: A prospective cohort study. Neurology. 2014;83;1601-9. DOI: 10.1212/WNL.0000000000000935. PMID: 25253749.

22. Cam BV, Fonsmark L, Hue NB, Phuong NT, Poulsen A, Heegaard ED. Prospective case control study of encephalopathy in children with dengue hemorrhagic fever. Am J Trop Med Hyg. 2001;65(6):848-51. DOI: 10.4269/ajtmh.2001.65.848. PMID: 11791985.

23. Kumar R, Prakash O, Sharma BS. Intracranial haemorrhage in dengue fever: management and outcome.A series of 5 cases and review of literature.Surg Neurol. 2009;72:429-33. DOI: 10.1016/j.surneu.2009.01.021.

24. Ellis EM, Sharp TM, Pérez-Padilla J, González L, Poole-Smith BK, Lebo E, et al. Incidence and Risk Factors for Developing Dengue-Associated Hemophagocytic Lymphohistiocytosis in Puerto Rico, 2008 - 2013. PLoS Negl Trop Dis. 2016;10(8):e0004939. https://doi.org/10.1371/journal.pntd.0004939.

25. Gupta VK, Gadpayle AK. Subclinical Cardiac Involvement in Dengue Hemorrhagic Fever. JIACM. 2010;11(2): $107-11$.

26. Miranda CH, Borges MC, Matsuno AK, Vilar FC, Gali LG, Volpe GJ, et al. Evaluation of cardiac involvement during dengue viral infection. Clin Inf Dis. 2013;57:812-9. DOI: 10.1093/cid/cit403.

27. Wichmann D, Kularatne S, Ehrhardt S, Wijesinghe S, Brattig NW, Abel W, et al. Cardiac involvement in dengue virus infections during the 2004/2005 dengue fever season in srilanka. Southeast Asian J Trop Med Public Health. 2009;40(4):727-30. PMID: 19842405.

28. Kularatne SAM, Pathirage MMK, Kumarasiri PVR, Gunasena S, Mahindawanse SI. Cardiac complications of a dengue feveroutbreak in Sri Lanka, 2005. Trans R Soc Trop. 2007;101:804-8. PMID: 19842405.

29. Wali JP, Biswas A, Chandra S, Malhotra A, Aggarwal P, Handa R, et al. Cardiac involvement in Dengue Haemorrhagic Fever. Int J Cardiol. 1998;64:31-6. DOI:10.1016/s0167-5273(98)00008-4. PMID: 9579814.

30. Kabra SK, Juneja R, Madhulika, Jain Y, Singhal T, Dar L, et al. Myocardial dysfunction in children with dengue haemorrhagic fever. Nat Med J India. 1998;11:59-61. PMID: 9624863 